\title{
Usage of Mushrooms in Culinary and Medicinal Purposes
}

\author{
Mohammad Azizur Rahman*, Tawhidur Rahman, Moshiur Rahman, Mirza Arif \\ Department of Biochemistry and Molecular Biology, Jahangirnagar University, Savar, Dhaka, Bangladesh.
}

*Corresponding Author: Mohammad Azizur Rahman, Department of Biochemistry and Molecular Biology, Jahangirnagar University, Savar, Dhaka, Bangladesh.

\section{Received Date: 28 September 2021 | Accepted Date: 21 December 2021 | Published Date: 03 January 2022}

Citation: Mohammad A Rahman, T Rahman, M Rahman, M Arif. (2022). Usage of Mushrooms in Culinary and Medicinal Purposes. Biomedical Research and Clinical Reviews. 6(1); DOI: 10.31579/2692-9406/087

Copyright: (C) 2022 Mohammad Azizur Rahman, This is an open-access article distributed under the terms of the Creative Commons Attribution License, which permits unrestricted use, distribution, and reproduction in any medium, provided the original author and source are credited.

\begin{abstract}
The present article reviews the history of mushroom uses in culinary, food and medicinal values; current status and future aspect of mushroom research. Mushrooms contain biologically active polysaccharides, lipid and proteins in fruit bodies, each of them has a distinct role in health as either nutritional value or medicinal elements. Immunostimulating polysaccharides found in mushrooms, are most important for modern medicine. Several of the mushroom biomolecules have undergone phase I, II, and III clinical trials and are used extensively and successfully throughout the world for the treatment of various cancers and other diseases. Medicinal functions played by the mushrooms include antitumor, antibacterial, antioxidant, antiparasitic, antidiabetic, detoxification, cardiovascular, antihypercholesterolemia, antiviral, antifungal, hepatoprotective, immunomodulating and free radical scavenging. The present review draws attention to nutritional and medicinal importance of mushroom as well as the problems and opportunity in the future development of mushroom research.
\end{abstract}

Key words: medicinal mushrooms; immunostimulating; nutrition; immunomodulating; antitumor; culinary

\section{Introduction}

Mushrooms have been considered as ingredient of gourmet cuisine across the globe; especially for their unique flavor and have been valued by humankind as a culinary wonder. More than 2,000 species of mushrooms exist in nature, but around 25 are widely accepted as food and few are commercially cultivated. Mushrooms are considered as a delicacy with high nutritional and functional value, and they are also accepted as nutraceutical foods; they are of considerable interest because of their organoleptic merit, medicinal properties, and economic significance [1]. However, there is not an easy distinction between edible and medical mushrooms because many of the common edible species have therapeutic properties and several used for medical purposes are also edible [2].

The most cultivated mushroom worldwide is Agaricus bisporus, followed by Lentinus edodes, Pleurotus spp., and Flammulina velutipes. Mushrooms production continuously increases, China being the biggest producer around the world [3]. However, wild mushrooms are becoming more important for their nutritional, sensory, and especially pharmacological characteristics [4].

Mushrooms could be an alternative source of new antimicrobial compounds, mainly secondary metabolites, such as terpenes, steroids, anthraquinones, benzoic acid derivatives, and quinolones, but also of some primary metabolites like oxalic acid, peptides, and proteins. Lentinus edodes is the most studied species and seems to have an antimicrobial action against both gram-positive and gram-negative bacteria [5].
They have a great nutritional value since they are quite rich in protein, with an important content of essential amino acids and fiber, poor fat but with excellent important fatty acids content (Table 1). Moreover, edible mushrooms provide a nutritionally significant content of vitamins (B1, B2, B12, C, D, and E) [6]. Thus, they could be an excellent source of many different nutraceuticals and might be used directly in human diet and to promote health for the synergistic effects of all the bioactive compounds present [7].

A large variety of mushrooms have been utilized traditionally in many different cultures for the maintenance of health, as well as in the prevention and treatment of diseases through their immunomodulatory and antineoplastic properties. In the last decade, the interest for pharmaceutical potential of mushrooms has been increased rapidly, and it has been suggested that many mushrooms are like mini-pharmaceutical factories producing compounds with miraculous biological properties [8]. In addition, the expanded knowledge of the molecular basis of tumorigenesis and metastasis has given the opportunity for discovering new drugs against abnormal molecular and biochemical signals leading to cancer [9]. In the Western world, the mushroom industry suffers from overproduction. Expectations are stronger than reality, and as a result, production is too high and prices are too low. Because bulk production has taken the lead, which not only happens in the West, overproduction occurs regularly. Low pricing influences the quality concept of consumers and hence their appreciation of mushrooms. This cannot continue without doing great harm to the socioeconomic structure of the industry. 
Therefore, measures have to be taken to introduce mushrooms as a true health food in the Western world. This may form a first step in the acceptance of mushroom extracts and mushroom-derived compounds as medicine in the prevention and cure of disease. The present review discusses the acceptance of mushrooms as health food and medicine and suggests pathways for necessary action. Lingzhi (Ganoderma lucidum) is a woody mushroom highly regarded in traditional medicine and is widely consumed in the belief that it promotes health and longevity, lowers the risk of cancer and heart disease and boosts the immune system [10]. However, objective scientific validation of the putative health benefits of Lingzhi in human subjects is lacking, and issues of possible toxicity must be addressed. The present double-blinded, placebo-controlled, cross-over intervention study investigated the effects of 4 weeks Lingzhi supplementation on a range of biomarkers for antioxidant status, coronary heart disease (CHD) risk, DNA damage, immune status, and inflammation, as well as markers of liver and renal toxicity. It was performed as a follow-up to a study that showed that antioxidant power in plasma increased after Lingzhi ingestion, and that $10 \mathrm{~d}$ supplementation was associated with a trend towards an improved CHD biomarker profile. In the present study, fasting blood and urine from healthy, consenting adults (n 18; aged 22-52 years) was collected before and after 4 weeks supplementation with a commercially available encapsulated Lingzhi preparation (1.44 g Lingzhi/d; equivalent to $13.2 \mathrm{~g}$ fresh mushroom/d) or placebo. No significant change in any of the variables was found, although a slight trend toward lower lipids was again seen, and antioxidant capacity in urine increased. The results showed no evidence of liver, renal or DNA toxicity with Lingzhi intake, and this is reassuring. The present study of the effects in healthy, well-nourished subjects provides useful, new scientific data that will support controlled intervention trials using at-risk subjects in order to assess the therapeutic effect of Lingzhi in the promotion of healthy ageing $[11,12]$. In this review it was aimed to determine the benefit of mushroom as food and medicinal purpose.

\section{Nutritional Value}

The nutritional value of edible mushrooms is due to their high protein, fiber, vitamin and mineral contents, and low-fat levels [13]. They are very useful for vegetarian diets because they provide all the essential amino acids for adult requirements; also, mushrooms have higher protein content than most vegetables. Besides, edible mushrooms contain many different bioactive compounds with various human health benefits [14].

It is important to remark that the growth characteristics, stage and postharvest condition may influence the chemical composition and the nutritional value of edible mushrooms. Also, great variations occur both among and within species [15]. Mushrooms contain a high moisture percentage that ranges between 80 and $95 \mathrm{~g} / 100 \mathrm{~g}$, approximately. As above mentioned, edible mushrooms are a good source of protein, 200$250 \mathrm{~g} / \mathrm{kg}$ of dry matter; leucine, valine, glutamine, glutamic and aspartic acids are the most abundant. Mushrooms are low-calorie foods since they provide low amounts of fat, $20-30 \mathrm{~g} / \mathrm{kg}$ of dry matter, being linoleic (C18:2), oleic (C18:1) and palmitic (C16:0) the main fatty acids. Edible mushrooms contain high amounts of ash, $80-120 \mathrm{~g} / \mathrm{kg}$ of dry matter (mainly potassium, phosphorus, magnesium, calcium, copper, iron, and zinc). Carbohydrates are found in high proportions in edible mushrooms, including chitin, glycogen, trehalose, and mannitol; besides, they contain fiber, $\beta$-glucans, hemicelluloses, and pectic substances. Additionally, glucose, mannitol, and trehalose are abundant sugars in cultivated edible mushrooms, but fructose and sucrose are found in low amounts. Mushrooms are also a good source of vitamins with high levels of riboflavin (vitamin B2), niacin, folates, and traces of vitamin C, B1, B12, $\mathrm{D}$ and $\mathrm{E}$. Mushrooms are the only nonanimal food source that contains vitamin $\mathrm{D}$ and hence they are the only natural vitamin $\mathrm{D}$ ingredients for vegetarians. Wild mushrooms are generally excellent sources of vitamin
D2 unlike cultivated ones; usually cultivated mushrooms are grown in darkness and UV-B light is needed to produce vitamin D2 [16, 17].

\section{Nutraceuticals}

In addition to the nutritional components found in edible mushrooms, some have been found to comprise important amounts of bioactive compounds. The content and type of biologically active substances may vary considerably in edible mushrooms; their concentrations of these substances are affected by differences in strain, substrate, cultivation, developmental stage, age, storage conditions, processing, and cooking practices [18].

The bioactive substances found in mushrooms can be divided into secondary metabolites (acids, terpenoids, polyphenols, sesquiterpenes, alkaloids, lactones, sterols, metal chelating agents, nucleotide analogs, and vitamins), glycoproteins and polysaccharides, mainly $\beta$-glucans. New proteins with biological activities have also been found, which can be used in biotechnological processes and for the development of new drugs, including lignocellulose-degrading enzymes, lectins, proteases and protease inhibitors, ribosome-inactivating proteins, and hydrophobins [19].

In China, many species of edible wild-grown mushrooms, that is Tricholoma matsutake, Lactarius hatsudake, Boletus aereus, are appreciated as food and also in traditional Chinese medicine. The rich amount of proteins, carbohydrates, essential minerals, and low energy levels contributes to considering many wild-grown mushrooms as good food for the consumer, which can virtually be compared with meat, eggs, and milk [20].

Numerous bioactive polysaccharides or polysaccharide-protein complexes from medicinal mushrooms appear to enhance innate and cellmediated immune responses and exhibit antitumor activities in animals and humans. A wide range of these mushroom polymers have been reported previously to have immunotherapeutic properties by facilitating growth inhibition and destruction of tumor cells. Several of the mushroom polysaccharide compounds have proceeded through clinical trials and are used extensively and successfully in Asia to treat various cancers and other diseases. A total of 126 medicinal functions are thought to be produced by selected mushrooms [21].

\section{Carbohydrates}

Polysaccharides are the best known and most potent mushroom derived substances with antitumor and immunomodulating properties. Data on mushroom polysaccharides have been collected from hundreds of different species of higher basidiomycetes; some specific carbohydrates with these properties have been quantified in different mushrooms: rhamnose, xylose, fucose, arabinose, fructose, glucose, mannose, mannitol, sucrose, maltose, and trehalose [22].

\section{Proteins}

Bioactive proteins are an important part of functional components in mushrooms and also have great value for their pharmaceutical potential. Mushrooms produce a large number of proteins and peptides with interesting biological activities such as lectins, fungal immunomodulatory proteins, ribosome inactivating proteins, antimicrobial proteins, ribonucleases, and laccases [23].

Lectins are nonimmune proteins or glycoproteins binding specifically to cell surface carbohydrates and in the past few years many mushroom lectins have been discovered [24]. They have many pharmaceutical activities and possess immunomodulatory properties, antitumoral, antiviral, antibacterial, and antifungal activity. Some of them exhibit highly potent antiproliferative activity toward some tumor cell lines 
(human leukemic T cells, hepatoma Hep G2 cells, and breast cancer MCF7 cells) [25].

Fungal immunomodulatory proteins are a new family of bioactive proteins isolated from mushrooms, which have shown a potential application as adjuvants for tumor immunotherapy mainly due to their activity in suppressing tumor invasion and metastasis [26].

\section{Lipids}

Polyunsaturated fatty acids are mostly contained in edible mushrooms; thus, they may contribute to the reduction of serum cholesterol. It is noteworthy that transisomers of unsaturated fatty acids have not been detected in mushrooms. The major sterol produced by edible mushrooms is ergosterol, which shows antioxidant properties. It has been observed that a diet rich in sterols is important in the prevention of cardiovascular diseases [27, 28, 29].

\section{Phenolic Compounds}

Phenolic compounds are secondary metabolites possessing an aromatic ring with one or more hydroxyl groups, and their structures can be a simple phenolic molecule or a complex polymer. They exhibit a wide range of physiological properties, such as antiallergenic, antiatherogenic, anti-inflammatory, antimicrobial, antithrombotic, cardioprotective, and vasodilator effects. The main characteristic of this group of compounds has been related to its antioxidant activity because they act as reducing agents, free radical scavengers, singlet oxygen quenchers, or metal ion chelators [30].

Phenolic compounds provide protection against several degenerative disorders, including brain dysfunction, cancer, and cardiovascular diseases. This property is related to their capacity to act as antioxidants; they can scavenge free radicals and reactive oxygen species. The process of oxidation is essential for living organisms; it is necessary for the production of energy. However, the generation of free radicals has been implicated in several human diseases. The phenolic compounds in mushrooms show excellent antioxidant capacity [31].

\section{Main Edible Mushrooms Worldwide}

\section{Agaricus}

A. bisporus, from the Agaricus genera, is the most cultivated mushroom worldwide (Figure 1). This group of edible mushrooms is nowadays widely used and studied for its medicinal and therapeutic properties lectin from A. bisporus and a protein from A. polytricha have been found to be potent immune stimulants; thus, these macromolecules may be considered for pharmaceutical utilization and these fungi may be classified as healthy food. A. bisporus extract has been shown to prevent cell proliferation in breast cancer [32].

A. blazei is an edible mushroom native to Brazil and it has been cultivated especially in Japan. It is a very popular basidiomycete known as "sun mushroom," and at these days it is consumed globally as food or in tea due to its medicinal properties. Its fruit bodies exhibit antimutagenic, anticarcinogenic, and immunostimulative activities; its extracts have also shown immunomodulatory, anticarcinogenic, and antimutagenic properties [33]. Additionally, it has been reported that this mushroom blocks the liver lipid peroxidation.

Al-Dbass et al. concluded that A. blazei is a natural source of antioxidant compounds and has hepatoprotective activities against liver damage. On the other hand, Hakime-Silva et al. [34] reported that the aqueous extract of this fungus is a possible source of free radical scavengers and stated that this fungus can be used as a pharmacological agent against oxidative stress and as a nutritional source. Also, it is known that this fungus is rich in $\beta$-glucans, steroids, tocopherols, and phenolic compounds [35].

Moreover, liquid extracts of this fungus inhibit cell proliferation in prostate cancer cells and oral supplementation suppressing significantly tumor growth without inducing adverse effects. A. blazei has been used as an adjuvant in cancer chemotherapy and various types of antileukemic bioactive components have been extracted from it [36].

In 2013, Carneiro et al. reported powder formulations from A. blazei and L. edodes with proteins, carbohydrates, and unsaturated fatty acids. These formulations may be used in low-calorie diets and have shown high antioxidant activity with high content of tocopherols and phenolic compounds. In view of the previous studies, this fungus has been used as a healthy food for the prevention of a range of illnesses including cancer, diabetes, arteriosclerosis, and chronic hepatitis [37].

A. subrufescens is called the "almond mushroom" for its almond taste, and it is cultivated in the US and has been incorrectly referred as A. blazei. It produces various bioactive compounds that have potential to treat many diseases and has been used as a medicinal food for the prevention of cancer, diabetes, hyperlipidemia, arteriosclerosis, and chronic hepatitis. Some of its beneficial properties are the reduction of tumor growth, antimicrobial and antiviral activities, immunostimulatory and antiallergy effects. The bioactive compounds isolated from this mushroom are mainly based on polysaccharides such as riboglucans, $\beta$-glucans, and glucomannans. The antitumor activity has been found in lipid fractions, that is, ergosterol [38].

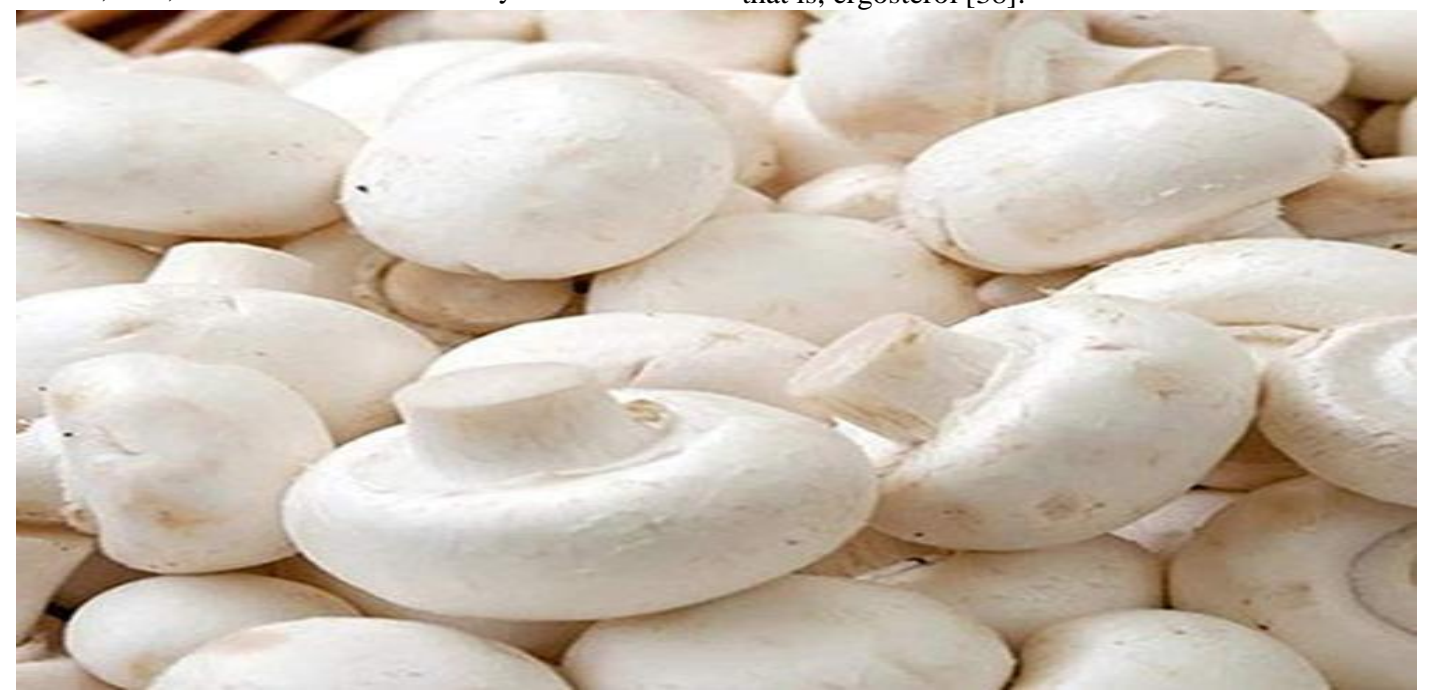

Figure 1: Agaricus 


\section{Lentinus}

L. edodes or "shiitake mushroom" has been used for many years to investigate functional properties and to isolate compounds for pharmaceutical use; this is because of its positive effects on human health. It has been utilized to alleviate the common cold for hundreds of years and some scientific evidence has supported this belief. Finimundy et al. have provided experimental information about the aqueous extracts of $L$. edodes as potential sources of antioxidant and anticancer compounds. These extracts significantly decreased cell proliferation on tumor as well [39].

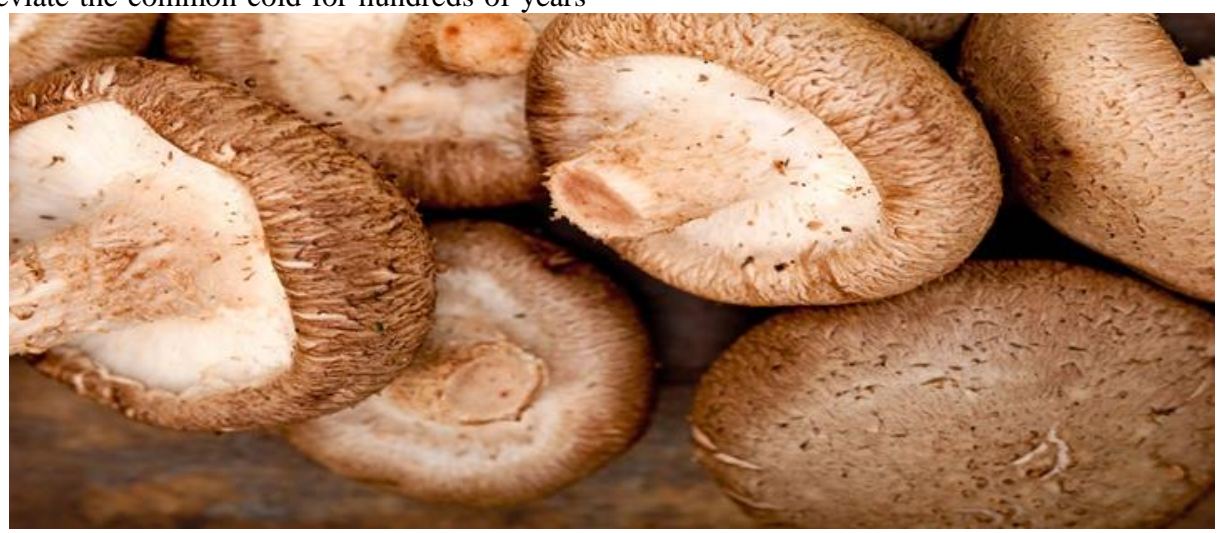

Figure 2: Lentinus

\section{Pleurotus}

This genus, also known as oyster mushrooms, has approximately 40 species (all are commonly edible and available). In addition to their nutritional value, they possess medicinal properties and other beneficial effects and health-promoting effects. Pleurotus species have been used by human cultures all over the world for many years [40].

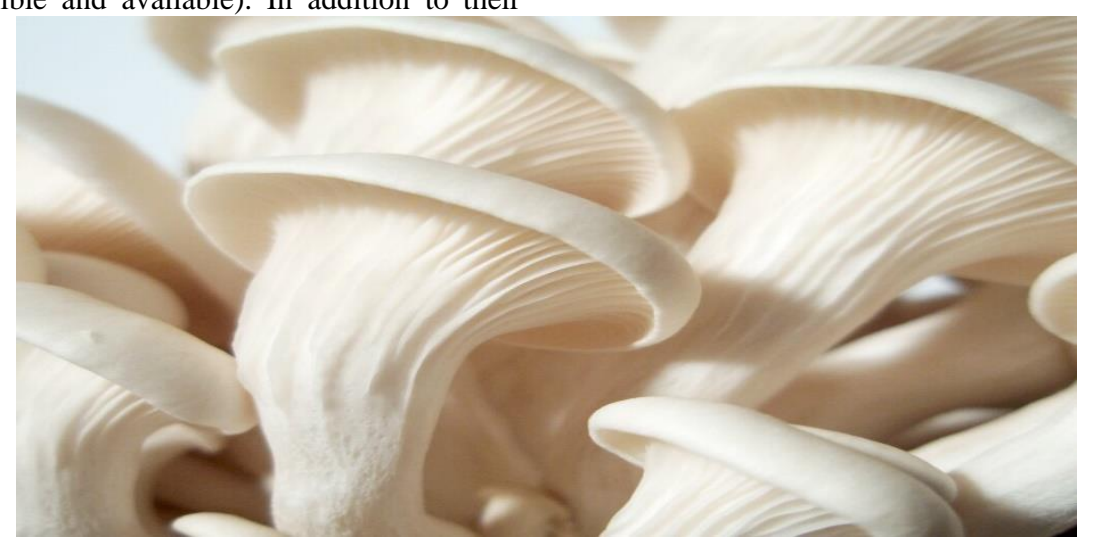

Figure 3: Pleurotus

\section{Ganoderma}

The "mushroom of immortality," commonly known as Lingzhi or Reishi, has been used in traditional Chinese medicine to improve health and longevity for thousands of years, as well as in the treatment of neurasthenia, hypertension, hepatopathy, and carcinoma. It is one of the most popular medicinal mushrooms in China, Japan, and Korea. It has been under modern biochemical and pharmacological research during the last decades. Modern pharmacological tests have also demonstrated some important characteristics of this fungus, such as immunomodulating, antiallergic, antiradiation, antitumor, anti-inflammatory, antiparasitic, and antioxidant properties. Some benefits for the cardiovascular, respiratory, endocrine, and metabolic systems have also been described [41].

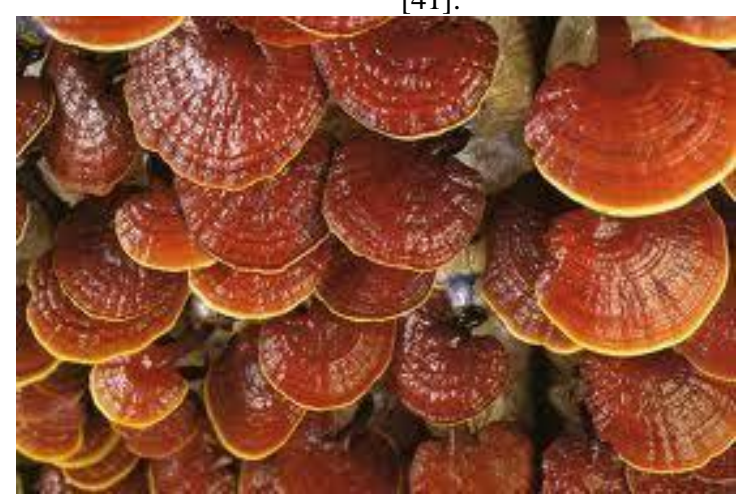

Figure 4: Ganoderma 


\section{Medicinal uses of Mushroom}

The main target of the present review is to draw attention to the current perspectives, advances, evidences, challenges, and future development of medicinal mushroom science in the 21 st century. Medicinal mushrooms and fungi are thought to possess approximately 130 medicinal functions, including antitumor, immunomodulating, antioxidant, radical scavenging, cardiovascular, anti-hypercholesterolemic, antiviral, antibacterial, anti-parasitic, antifungal, detoxification, hepatoprotective, and antidiabetic effects. Many, if not all, higher Basidiomycetes mushrooms contain biologically active compounds in fruit bodies, cultured mycelium, and cultured broth. Special attention is paid to mushroom polysaccharides. The data on mushroom polysaccharides and different secondary metabolites are summarized for approximately 700 species of higher hetero- and homobasidiomycetes [42]. Numerous bioactive polysaccharides or polysaccharide-protein complexes from the medicinal mushrooms described appear to enhance innate and cellmediated immune responses, and exhibit antitumor activities in animals and humans. Whilst the mechanism of their antitumor actions is still not completely understood, stimulation and modulation of key host immune responses by these mushroom compounds appear central. Polysaccharides and low-molecular-weight secondary metabolites are particularly important due to their antitumor and immunostimulating properties. Several of the mushroom compounds have been subjected to Phase I, II, and III clinical trials, and are used extensively and successfully in Asia to treat various cancers and other diseases. Special attention is given to many important unsolved problems in the study of medicinal mushrooms [43].

Polyporus umbellatus is a medicinal mushroom belonging to the family Polyporaceae which forms characteristic underground sclerotia. These sclerotia have been used in Traditional Chinese Medicine for centuries and are used to treat edema and promote diuretic processes. Over the past few decades, researchers have found this taxon to contain many bioactive compounds shown to be responsible for antitumor, anticancer, antioxidant, free radical scavenging, immune system enhancement and antimicrobial activities. Due to its promising medicinal value, $P$. umbellatus is used as an ingredient in many medicinal products and food supplements. Thus demand for P. umbellatus has increased. To supply the high global demand, P. umbellatus is cultivated under natural or industrial conditions. In this review we discuss optimal conditions for the cultivation and culture of $P$. umbellatus. We also focus on the medicinal uses of $P$. umbellatus, the diversity of bioactive metabolites with various pharmacological properties and the medicinal products of great interest for health care or as alternative drugs [44].

Often considered vegetables, mushrooms are neither plants nor animals. They belong to a unique kingdom of fungi. Unlike plants that make their food using sunlight and animals that eat their food, fungi have a unique way of obtaining nutrition. They have certain thread-like structures called mycelia (singular mycelium) that grow into or around the food source and release digestive enzymes to break down food externally that is then absorbed by mycelia. Mushrooms are fruiting bodies of the mycelium [45].

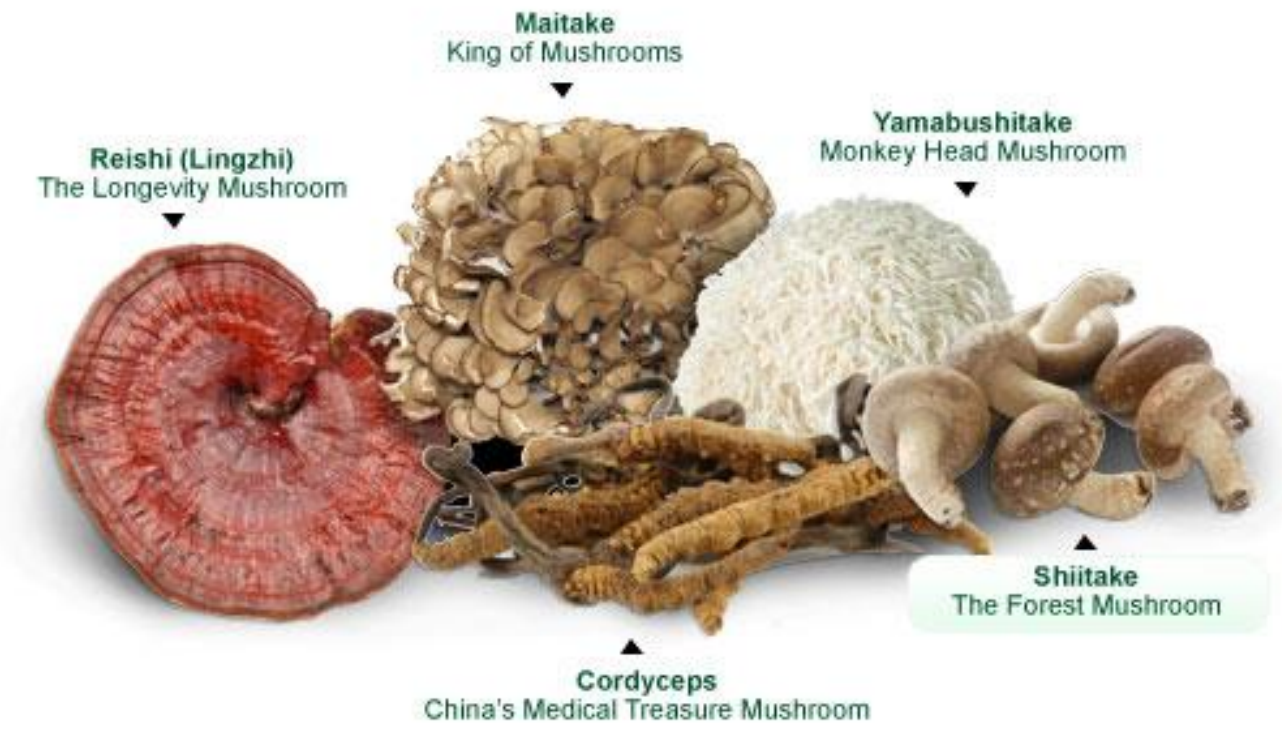

Figure 5: Medicinal uses of Mushroom

Being addressed with terms such as "the elixir of life" and "foods for the Gods," mushrooms are truly packed with several health-boosting nutrients. They are the richest natural source of vitamin D for vegetarians. They are low in calories and have virtually no cholesterol or fat. They are rich in protein, fiber, vitamins (such as riboflavin [vitamin B2], niacin, folate and traces of vitamins B1, B12, C, D and E), potassium, phosphorus and selenium. The protein content of mushrooms is higher than that of most vegetables. Not just in quantity, proteins in mushrooms are also rich in quality because they provide most of the essential amino acids required in the diet. Mushrooms are full of antioxidants including phenolic compounds that protect you from allergies, heart disease, infections, inflammatory diseases, high blood pressure and cancer. Because mushrooms are rich in fiber and low in calories, they are great for weight management [46].

Mushrooms are being marketed as supplements or medicinal mushrooms with claims that they can promote brain and heart health and prevent cancer. There are, however, insufficient clinical trials to support these claims. Although good for health, you must not replace mushrooms with prescribed medicines. Some of the mushrooms considered best for human health include haga mushroom (Inonotus obliquus): It is also called "the king of medicinal mushrooms." It is not a true mushroom but a mass of mycelia (called sclerotium). This mushroom is rich in various antioxidants. It boosts immunity, brain health and liver health and may thus increase life span [46]. 
Lion's mane mushroom (Hericium erinaceus): It is also called "the mushroom for the mind" because of its role in promoting brain health and nerve function. It contains important compounds such as beta-glucans known for their tumor-protecting, immune-boosting and brain-protective properties. It may play a role in protecting against diseases such as Parkinson's and Alzheimer's.

Reishi mushroom (Ganoderma lucidum): It is also called "the mushroom for immortality." It boosts immunity, promotes restful sleep, fights fatigue and reduces stress.

Turkey tail mushroom (Trametes versicolor and Coriolus versicolor): It is also called "the mushroom of several colors." It is one of the most popular medicinal mushrooms. It boosts immunity and is said to fight cancer cells. It also promotes gut health.

Shiitake mushroom (Lentinula edodes): It is also called "the fragrant mushroom." It is known for its delicious flavor. It reduces inflammation in the body and boosts liver function, heart health and immunity.

Cordyceps mushroom (Cordyceps sinensis): It is also called "the caterpillar mushroom." It is known for its role in increasing energy production inside the cells. It may protect from allergies and boost lung health.

Maitake mushroom (Grifola frondosa): It is also called "the dancing mushroom." It is famous for boosting immunity, regulating blood sugar and cholesterol levels, regulating blood pressure and aiding weight loss.

\section{Conclusions}

There is no doubt that sustainability oriented consumption is a megatrend that influences the consumer habits of mainly older generations and family with children. Mushrooms are still controversial: Even though their positive health effects are undeniable, their consumption varies by cultures and countries. The majority of consumers consider mushrooms a supplementary food source, which coincides with local traditions. It is significant that mushrooms having medicinal and functional properties is the second most important consideration and this is due to active marketing by some producers and chambers of commerce; however, that also shows that the increasing share of older population and families with higher education possess positive mindsets. Future marketing activities must target further populations and spread the recognition of mushrooms as an important food source.

\section{Acknowledgement}

Authors gratefully acknowledge the grant-in-aid provided by Jahangirnagar University, Bangladesh and University Grants Committee of Bangladesh.

\section{Reference}

1. Valverde ME, Hernández-Pérez T, Paredes-López O. (2015). Edible mushrooms: improving human health and promoting quality life. International journal of microbiology.

2. Akpaja EO, Isikhuemhen OS, Okhuoya JA. (2003). Ethnomycology and usage of edible and medicinal mushrooms among the Igbo people of Nigeria. International Journal of medicinal mushrooms. 5(3).

3. Reis FS, Barros L, Martins A, Ferreira IC. (2012). Chemical composition and nutritional value of the most widely appreciated cultivated mushrooms: an inter-species comparative study. Food and Chemical Toxicology. 50(2):191197.

4. Leskosek-Cukalovic I, Despotovic S, Lakic N, Niksic M, Nedovic V, Tesevic V. (2010). Ganoderma lucidum medical mushroom as a raw material for beer with enhanced functional properties. Food Research International. 43(9):2262-2269.
5. Alves MJ, Ferreira IC, Dias J, Teixeira V, Martins A, Pintado M. (2012). A review on antimicrobial activity of mushroom (Basidiomycetes) extracts and isolated compounds. Planta medica. 78(16):1707-1718.

6. Mattila P, Könkö K, Eurola M, Pihlava JM, Astola J, Vahteristo L, Hietaniemi V, Kumpulainen J, Valtonen M, Piironen V. (2001). Contents of vitamins, mineral elements, and some phenolic compounds in cultivated mushrooms. Journal of agricultural and food chemistry. 49(5):2343-2348.

7. Liu RH. (2003). Health benefits of fruit and vegetables are from additive and synergistic combinations of phytochemicals. The American journal of clinical nutrition. 78(3):517-520.

8. Kadhila NP, Sekhoacha M, Tselanyane ML, Chinsembu K. (2018). Antiplasmodial activities in mushrooms. International Journal of Vector Borne Diseases. 139-142.

9. Zaidman BZ, Yassin M, Mahajna J, Wasser SP. (2005). Medicinal mushroom modulators of molecular targets as cancer therapeutics. Applied Microbiology and Biotechnology. 67(4):453-468.

10. Leskosek-Cukalovic I, Despotovic S, Lakic N, Niksic M, Nedovic V, Tesevic V. (2010). Ganoderma lucidum-medical mushroom as a raw material for beer with enhanced functional properties. Food Research International. 43(9):2262-2269.

11. Figlas D, Curvetto N. Medicinal Mushroom Reishi (Ganoderma Lucidum). Main Toxicity And Allergenicity Studies. Dosage, Posology and Side Effects.

12. Lau Altamiranda RW. Immunomodulatory, anti-inflammatory and anti-microbial effects of selected dietary agents: a study using a biomarker approach.

13. Agrahar-Murugkar D, Subbulakshmi GJ. (2005). Nutritional value of edible wild mushrooms collected from the Khasi hills of Meghalaya. Food Chemistry. 89(4):599-603.

14. Thakur MP, Singh HK. (2013). Mushrooms, their bioactive compounds and medicinal uses: A review. Medicinal PlantsInternational Journal of Phytomedicines and Related Industries. 5(1):1-20.

15. Bano Z, Rajarathnam S, Steinkraus KH. (1988). Pleurotus mushrooms. Part II. Chemical composition, nutritional value, post-harvest physiology, preservation, and role as human food. Critical Reviews in Food Science \& Nutrition. 27(2):87-158.

16. Kalač P. (2009). Chemical composition and nutritional value of European species of wild growing mushrooms: A review. Food chemistry. 113(1):9-16.

17. Watanabe F, Yabuta Y, Tanioka Y, Bito T. (2013). Biologically active vitamin B12 compounds in foods for preventing deficiency among vegetarians and elderly subjects. Journal of agricultural and food chemistry. 61(28):6769-6775.

18. Nagulwar MM, More DR, Mandhare LL. (2020). Nutritional Properties and Value Addition of Mushroom: A review. The Pharma Innovation Journal. 9:395-398.

19. Erjavec J, Kos J, Ravnikar M, Dreo T, Sabotič J. (2012). Proteins of higher fungi-from forest to application. Trends in biotechnology. 30(5):259-273.

20. Alzand KI, Bofaris MS, Ugis A. (2019). Chemical Composition and Nutritional Value of Edible Wild Growing Mushrooms: A Review. World J. Pharm. Res. 8(3):31-46.

21. Chang ST, Wasser SP. (2012). The role of culinary-medicinal mushrooms on human welfare with a pyramid model for human health. International journal of medicinal mushrooms. 14(2).

22. Heleno SA, Barros L, Martins A, Queiroz MJ, Santos-Buelga C, Ferreira IC. (2012). Phenolic, polysaccharidic, and lipidic fractions of mushrooms from Northeastern Portugal: chemical compounds with antioxidant properties. Journal of Agricultural and Food Chemistry. 60(18):4634-4640. 
23. Xu X, Yan H, Chen J, Zhang X. (2011). Bioactive proteins from mushrooms. Biotechnology advances. 29(6):667-674.

24. Singh RS, Bhari R, Kaur HP. (2010). Mushroom lectins: current status and future perspectives. Critical Reviews in Biotechnology. 30(2):99-126.

25. Patel S, Goyal A. (2012). Recent developments in mushrooms as anti-cancer therapeutics: a review. 3 Biotech. 2(1):1-5.

26. De Silva DD, Rapior S, Fons F, Bahkali AH, Hyde KD. (2012). Medicinal mushrooms in supportive cancer therapies: an approach to anti-cancer effects and putative mechanisms of action. Fungal Diversity. 55(1):1-35.

27. Nagulwar MM, More DR, Mandhare LL. (2020). Nutritional Properties and Value Addition Of Mushroom: A review. The Pharma Innovation Journal. 9:395-398.

28. Rasmussen RS, Morrissey MT. (2007). Marine biotechnology for production of food ingredients. Advances in food and nutrition research. 52:237-292.

29. Harwood J. (2012). Lipids in plants and microbes. Springer Science \& Business Media.

30. Palacios I, Lozano M, Moro C, D'arrigo M, Rostagno MA, Martínez JA, García-Lafuente A, Guillamón E, Villares A. (2011). Antioxidant properties of phenolic compounds occurring in edible mushrooms. Food Chemistry. 128(3):674678.

31. Hung PV, Nhi NN. (2012). Nutritional composition and antioxidant capacity of several edible mushrooms grown in the Southern Vietnam. International Food Research Journal. 19(2):611.

32. Atila F, Owaid MN, Shariati MA. (2021). The nutritional and medical benefits of Agaricus bisporus: a review. Journal of Microbiology, Biotechnology and Food Sciences. 281-286.

33. Delmanto RD, de Lima PL, Sugui MM, da Eira AF, Salvadori DM, Speit G, Ribeiro LR. (2001). Antimutagenic effect of Agaricus blazei Murrill mushroom on the genotoxicity induced by cyclophosphamide. Mutation Research/Genetic Toxicology and Environmental Mutagenesis. 496(1-2):15-21.

34. Cristine da Silva de Souza A, Gesser Correa V, de Almeida Goncalves G, Assuncao Soares A, Bracht A, Marina Peralta R. (2017). Agaricus blazei bioactive compounds and their effects on human health: benefits and controversies. Current pharmaceutical design. 23(19):2807-2834.
35. Muszyńska B, Kała K, Lazur J, Włodarczyk A. (2020). Imleria badia culinary-medicinal mushroom with interesting biological properties. Food Bioscience. 29:100663.

36. Patel S, Goyal A. (2012). Recent developments in mushrooms as anti-cancer therapeutics: a review. 3 Biotech. 2(1):1-5.

37. Mohamed AM. (2008). The ameliorative actions of Agaricus blazei mushroom against rat liver oxidative damage and fibrosis induced by carbon tetrachloride. International Journal of Biotechnology \& Biochemistry. 4(4):303-324.

38. Mizuno M, Minato KI, Ito H, Kawade M, Terai H, Tsuchida H. (1999). Anti-tumor polysaccharide from the mycelium of liquid-cultured Agaricus blazei mill. IUBMB Life. 47(4):707714.

39. Chang R. (1996). Functional properties of edible mushrooms. Nutrition Reviews. 54(11):S91.

40. Golak-Siwulska I, Kałużewicz A, Spiżewski T, Siwulski M, Sobieralski K. (2018). Bioactive compounds and medicinal properties of Oyster mushrooms (Pleurotus sp.). Folia Horticulturae. 30(2):191-201.

41. Cherian E, Sudheesh NP, Janardhanan KK, Patani G. (2009). Free radical scavenging and mitochondrial antioxidant activities of Reishi-Ganoderma lucidum (Curt: Fr) P. Karst and Arogyapacha-Trichopus zeylanicus Gaertn extracts. Journal of basic and clinical physiology and pharmacology. 20(4):289308.

42. Wasser SP. (2017). Medicinal mushrooms in human clinical studies. Part I. Anticancer, oncoimmunological, and immunomodulatory activities: a review. International Journal of Medicinal Mushrooms. 19(4).

43. Chang ST, Wasser SP. (2012). The role of culinary-medicinal mushrooms on human welfare with a pyramid model for human health. International journal of medicinal mushrooms. 14(2).

44. Wasser SP, Sokolov D, Reshetnikov SV, Timor-Tismenetsky M. (2000). Dietary supplements from medicinal mushrooms: diversity of types and variety of regulations. International Journal of Medicinal Mushrooms. 2(1).

45. Das A, Prasad R, Bhatnagar K, Lavekar GS, Varma A. (2006). Synergism between medicinal plants and microbes. Microbes: Health and Environment, Anshan, UK. 31:13-64.

46. Null G, Feldman M. (2011). The health-boosting properties of Super Foods. Townsend Letter. 62-67.

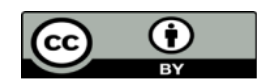

This work is licensed under Creative Commons Attribution 4.0 License
To Submit Your Article Click Here:

Submit Manuscript
Ready to submit your research? Choose Auctores and benefit from:

$>$ fast, convenient online submission

$>$ rigorous peer review by experienced research in your field

$>$ rapid publication on acceptance

$>$ authors retain copyrights

$>$ unique DOI for all articles

$>$ immediate, unrestricted online access

At Auctores, research is always in progress.

Learn more https://www.auctoresonline.org/journals/biomedical-research-andclinical-reviews- 